\title{
Karnofsky Performance Status 70
}

National Cancer Institute

\section{Source}

National Cancer Institute. Karnofsky Performance Status 70. NCI Thesaurus. Code C105711.

Cares for self; unable to carry on normal activity or do active work. 